\title{
Effects of yeast inoculation on volatile compound production by grape marcs
}

\author{
Barbara Bovo • Federico Fontana • Alessio Giacomini • \\ Viviana Corich
}

Received: 22 April 2010 / Accepted: 26 July 2010 / Published online: 14 August 2010

(C) Springer-Verlag and the University of Milan 2010

\begin{abstract}
Grape marcs are a by-product of winemaking that can be used for production of Grappa, a traditional Italian spirit. This plant material needs to undergo a fermentation process before distillation to allow production of ethanol from residual sugar and volatile aromatic compounds. To study the possible effect of selected yeast inocula on the fermentation process and subsequent quality of the distillate, a laboratory-scale fermentation of grape marcs was performed. The inoculated yeasts proved to be good colonizers of grape pomace and contributed markedly to rapid sugar consumption, which was completed within 5 days. Fermentation products were analysed by gaschromatography. A time course analysis performed to determine the impact of the inoculated strains on the main aromatic compounds that are concentrated in the product after distillation provided evidence of a positive effect of yeast inoculation.
\end{abstract}

Keywords Grappa · Fermentation · Gas chromatography . Saccharomyces

\section{Introduction}

Grappa is a traditional alcoholic beverage made in Italy (EEC 1989) by distillation of grape marc - a by-product of the winemaking process containing skins, seeds, and, in

This paper is part of the special issue "Wine microbiology and safety: from the vineyard to the bottle (Microsafetywine)", 19-20 November 2009, Martina Franca (Italy).

B. Bovo $\cdot$ F. Fontana $\cdot$ A. Giacomini $(\triangle) \cdot$ V. Corich Dipartimento di Biotecnologie Agrarie, Università di Padova, viale dell'Università 16 ,

35020 Padua, Italy

e-mail: alessio.giacomini@unipd.it some cases, stalks. After separation from must, grape pomace is usually pressed to drain out excess liquid and then delivered to the distillery. Sugars of marcs from red grapes are partially fermented to ethanol during the winemaking process, and such material can therefore be distilled within a few days. In the case of marcs from white grape varieties, complete fermentation occurs only following an appropriate period of storage, lasting from a few days to several weeks, inside concrete tanks, stainless steel containers or horizontal plastic tunnels that favour anaerobic conditions (Da Porto 2002). Sugar degradation and alcohol production are the main chemical processes occurring during this period, carried out mainly by the activity of yeasts. Nevertheless, a large number of other molecules with either positive or negative effects can develop from the activity of the indigenous microflora. To avoid off-flavours and production of toxic compounds from anomalous fermentation and bacterial spoilage that could affect the quality of the future distillate, distilleries have adopted technological approaches such as $\mathrm{pH}$ adjustment, temperature control, anaerobic environment setup and microbial population management, to avoid product spoilage. In most cases, bacterial proliferation is prevented by acidification treatment through addition of dilute sulphuric acid (Da Porto 2002). A seemingly promising approach for increasing spirit quality introduced recently is the inoculation of selected yeast strains into the marcs at the moment of storage; some producers inoculate pomace with commercial dried yeasts chosen from among those sold for winemaking. However, no studies on the exploitation of yeast strains isolated directly from grape marcs, which could possess traits peculiar to distillate production, have so far been reported.

This work represents the first report on the development of a yeast-guided fermentation process of grape pomace at laboratory scale. The effects of the yeast strain inocula were 
evaluated in terms of their ability to prevail on the resident microflora and to completely degrade sugars. A single gaschromatographic run allowed determination of volatile compounds, both varietal and yeast-related, obtained from marc distillation. A first insight into the differences between the aromatic profile of inoculated and non-inoculated grape pomace and its evolution during storage is provided.

\section{Materials and methods}

\section{Raw material}

Prosecco grape marcs were collected, immediately after crushing, from the vineyards of the Oenological Institute "G.B. Cerletti" in Conegliano Veneto (Italy) and kept frozen until required.

Yeast strain growth and isolation conditions

Four strains of Saccharomyces cerevisiae were used to inoculate grape marcs, namely the commercial yeast strain FR95 from the product Blastosel FR95 (Perdomini, Italy) and the strains AR-1, NM-12 and TV-15, isolated from grape marcs of different origin. Yeasts were grown in YPD medium (yeast extract $10 \mathrm{~g} / \mathrm{l}$, peptone $10 \mathrm{~g} / \mathrm{l}$, dextrose $20 \mathrm{~g} / \mathrm{l}$ ) at $30^{\circ} \mathrm{C}$ for $24 \mathrm{~h}$.

Grape marc fermentations were carried out in 100-ml Erlenmeyer flasks plugged with a one-hole stopper into which a J-shaped tube was inserted. Flasks were filled with $110 \mathrm{~g}$ grape marc, then heat treated for $20 \mathrm{~min}$ at $72^{\circ} \mathrm{C}$ in a water bath. Each flask was inoculated with $1 \times 10^{6}-3 \times 10^{6}$ cells/g from 24-h cultures in YPD medium and incubated at $20^{\circ} \mathrm{C}$ for 8 days. Three separate replicates were performed.

For yeast isolation, $5 \mathrm{~g}$ grape pomace was collected from each flask, dispersed in $50 \mathrm{ml}$ sterile PBS buffer $(\mathrm{NaCl} 8 \mathrm{~g} / \mathrm{l}$, $\mathrm{KCl} 0.2 \mathrm{~g} / \mathrm{l}, \mathrm{Na}_{2} \mathrm{HPO}_{4} 1.44 \mathrm{~g} / \mathrm{l}, \mathrm{KH}_{2} \mathrm{PO}_{4} 0.24 \mathrm{~g} / \mathrm{l}$ ) and, after appropriate decimal dilutions, plated on WL (Wallerstein Laboratory, Oxoid, Italy) medium containing $100 \mu \mathrm{g} / \mathrm{ml}$ chloramphenicol to contain bacterial growth and incubated at $30^{\circ} \mathrm{C}$ for 2 days.

\section{Restriction analysis of mitochondrial DNA}

Isolates from inoculated grape marcs were characterized by mitochondrial (mt)DNA analysis as described by Querol et al. (1992) with the following modification for yeast DNA extraction: a loopful of cells grown on YM plates was resuspended in $500 \mu \mathrm{TE}(50 \mathrm{mM}$ Tris, $20 \mathrm{mM}$ EDTA, $\mathrm{pH}$ 7.4) containing $0.3 \mathrm{~g}$ sterile glass beads $(425-600 \mu \mathrm{m}$, Sigma, Milan, Italy). The suspension was vortexed vigorously for $3 \mathrm{~min}$ before adding $50 \mu \mathrm{l} 10 \%$ SDS and incubating at $65^{\circ} \mathrm{C}$ for $30 \mathrm{~min}$. After addition of $200 \mu \mathrm{l} 5 \mathrm{M}$ potassium acetate, tubes were incubated on ice for $30 \mathrm{~min}$ and then centrifuged at $16,000 \mathrm{~g}$ for $5 \mathrm{~min}$. The supernatant was transferred to sterile $1.5 \mu \mathrm{l}$ Eppendorf tubes where $600 \mu \mathrm{l}$ cold isopropanol were added. After incubation at room temperature for $5 \mathrm{~min}$, tubes were centrifuged at $16,000 \mathrm{~g}$ for $10 \mathrm{~min}$. The pellet was washed with $500 \mu 170 \%$ ethanol, centrifuged for $5 \mathrm{~min}$ at $16,000 \mathrm{~g}$, dried under vacuum at $37^{\circ}$ $\mathrm{C}$ for $1 \mathrm{~h}$ and then resuspended in $50 \mu \mathrm{l}$ sterile water. After addition of $1.5 \mu \mathrm{l}$ RNase solution $(10 \mathrm{mg} / \mathrm{ml}$, Amersham Bioscience, Milan, Italy) and incubation at room temperature for $20 \mathrm{~min}$, samples were stored at $-20^{\circ} \mathrm{C}$. Yeast DNA digestion was carried out in $15 \mu \mathrm{l}$ volume using $300 \mathrm{ng}$ DNA and $20 \mathrm{U}$ HinfI restriction endonuclease (Amersham Bioscience), which is known to have a large number of sites within yeast nuclear DNA and only a few in mtDNA (Querol et al. 1992). Restriction fragments were separated by $1 \%(\mathrm{w} / \mathrm{v})$ agarose gel electrophoresis in $0.5 \times \mathrm{TBE}(44.5 \mathrm{mM}$ Tris-HCl, $44.5 \mathrm{mM}$ boric acid, $1 \mathrm{mM}$ EDTA, $\mathrm{pH} 8.3$ ) and the resulting profiles were analysed with the pattern analysis software package GelComparII (http://www.applied-maths. com/gelcompar/gelcompar.htm), using the Dice coefficient (Dice 1945).

\section{D1/D2 region sequencing}

The D1/D2 domain was amplified using primers NL1 (5'-GCATAT CAATAA GCG GAG GAA AAG - $3^{\prime}$ ) and NL4 (5'-GGT CCG TGT TTC AAG ACG G - 3') according to the protocol described by Kurtzman and Robnett (1998). Amplification products were checked for purity by agarose gel electrophoresis and then subjected to sequencing. Species were identified after BLASTN alignment (www. ncbi.nlm.nih.gov/BLAST) of the obtained sequences with those present in the GenBank public database. A minimum sequence similarity level of $98 \%$ was considered for taxonomic attribution.

Technological characteristics of selected yeasts

Fermentative vigour, in terms of the ability to start fermentation promptly, was determined routinely by the following method: yeast strains were inoculated at $1.5 \times 10^{6} \mathrm{cells} / \mathrm{ml}$ in flasks containing $100 \mathrm{ml}$ synthetic must prepared as described by Delfini (1995) with $0.3 \mathrm{~g} / 1\left(\mathrm{NH}_{4}\right)_{2} \mathrm{SO}_{4}, 0.3 \mathrm{~g} / 1\left(\mathrm{NH}_{4}\right)_{2} \mathrm{HPO}_{4}$, $200 \mathrm{~g} / 1$ glucose, $0.2 \mathrm{~g} / 1$ hydrolysed casein, $2 \mathrm{~g} / 1$ malic acid, $\mathrm{pH} 3.5$, and incubated without agitation at $25^{\circ} \mathrm{C}$.

Fermentative vigour, in terms of the amount of glucose consumed after $48 \mathrm{~h}$ of incubation, was determined by measuring culture weight loss multiplied by the coefficient 2.118 (Delfini 1995). The level of variability among replicates, on the basis of hundreds of determinations performed, was always lower than $0.4 \mathrm{~g} / 100 \mathrm{ml}$ must. This value was therefore taken as a reference for experimental variation. 
At the end of fermentations, a simple sensory evaluation was performed by a panel of five trained judges. Each panellist could give a positive, neutral or negative evaluation when the presence of fermentative aromas, no defect, or negative flavour (acetic acid and/or sulphur notes), respectively, were perceived. Each final score was expressed as the evaluation most frequently given by the panellists.

To evaluate hydrogen sulphide production, strains were grown on Biggy Agar medium according to Zambonelli (2003). After $48 \mathrm{~h}$ of incubation at $25^{\circ} \mathrm{C}$, the intensity of the brown colour was considered proportional to $\mathrm{H}_{2} \mathrm{~S}$ production.

Sulphur dioxide resistance was determined in synthetic must at $\mathrm{pH} 3.2$ with increasing $\mathrm{SO}_{2}$ content. Potassium metabisulphite was added to obtain the following doses of $\mathrm{SO}_{2}: 0,50,100$ and $200 \mathrm{mg} / \mathrm{l}$. Cultures of $10^{7}$ cells $/ \mathrm{ml}$ were used to inoculate $15-\mathrm{ml}$ tubes containing synthetic must with different concentration of $\mathrm{SO}_{2}$ to reach a final cell concentration of $10^{5}$ cells $/ \mathrm{ml}$. Strain resistance was evaluated by measuring the culture optical density at $600 \mathrm{~nm}$ after $48 \mathrm{~h}$ of incubation at $25^{\circ} \mathrm{C}$.

Screening of the $\beta$-glucosidase activity of whole cells was carried out using 4-methylumbelliferil- $\beta$-D-glucopyranoside (4-MUG) as substrate in black 96-well microtiter plates (Greiner Bio-One, Frickenhausen, Germany), with flat transparent bottom (200- $\mu$ l capacity), following the method reported by Fia et al. (2005) with some modifications. A 24-h-old culture on YPD was used to inoculate $10 \mathrm{ml}$ synthetic must at $\mathrm{pH} 3.0$, with a cell concentration of $2 \times 10^{6}$ cell $/ \mathrm{ml}$. After a $24 \mathrm{~h}$ incubation the test was performed in triplicate, at $\mathrm{pH} 3.5 \mathrm{in} 0.05 \mathrm{~mol} / \mathrm{l}$ sodium acetate buffer. The fluorescence emitted by 4-methylumbelliferone (4-MU) was detected using a spectrofluorimeter (Spectrafluor Tecan, Salzburg, Austria). To establish a relationship between fluorescence values emitted by 4-MU and enzymatic activity, a calibration curve was constructed by using increasing concentration of the reaction product 4-MU $(0,0.1,1,5,10$ and $50 \mu \mathrm{M}$ ), prepared in sodium acetate.

Distillation of grape pomace and aromatic compound concentration

Volatile fermentation compounds were extracted from $100 \mathrm{~g}$ grape marc by distillation under current steam with Cazenave equipment up to a distillate volume of $40 \mathrm{ml}$. Aliquots of $20 \mathrm{ml}$ from each distillate were added to $8 \mathrm{~g}$ ammonium sulphate and extracted with $7.5 \mathrm{ml}$ dichloromethane.

Determination of sugar and alcohol content

Sugar content of marcs was determined by Fehling titration of aqueous extracts from pomace residues after distillation (De Rosa and Castagner 1994). Three independent measurements were performed for each sample. Alcohol content of the distillate was determined with a commercial kit (Boehringer Mannheim/R-Biopharm, Mannheim, Germany).

\section{Gas chromatography}

Volatile and fermentation compounds produced in Prosecco must were determined in triplicate by gas-chromatography. External standard solutions $\mathrm{A}$ and $\mathrm{B}$ were used and chemicals were purchased from Sigma-Aldrich and Fluka (Milano, Italy) with a purity higher than $98 \%$. Solution A was prepared in water by adding methanol, acetaldehyde, n-propanol, n-butanol, isobutanol, isoamyl alcohol, $\beta$ phenylethanol, 2-butanol, acetic acid, benzaldehyde, hexanal, trans-2-hexenal, and acetoin. Solution B was prepared in absolute ethanol and contained: ethyl acetate, isoamyl acetate, phenylacetate, ethyl caproate, ethyl caprylate, geraniol, linalol, nerol, and $\beta$-damascon. 2-Octanol was used as internal standard at $6 \mathrm{mg} / \mathrm{ml}$ concentration in ethanol. The analytical system used was a Trace GC2000 Thermo Finnigan gas chromatograph equipped with a fused silica capillary column Varian CP WAX $57 \mathrm{CB}$, and a split-splitless automatic injector coupled with a FID detector. Injector temperature $250^{\circ} \mathrm{C}$; volume injected $2 \mu \mathrm{l}$; flux of helium carrier gas of $1.8 \mathrm{ml} / \mathrm{min}$. Oven temperature program: $5 \mathrm{~min}$ at $35^{\circ} \mathrm{C}, 2^{\circ} \mathrm{C} / \mathrm{min}$ to $68^{\circ} \mathrm{C}, 2 \mathrm{~min}$ at $68^{\circ} \mathrm{C}, 5^{\circ} \mathrm{C} / \mathrm{min}$ to $100^{\circ} \mathrm{C}$, $2 \mathrm{~min}$ at $100^{\circ} \mathrm{C}, 3^{\circ} \mathrm{C} / \mathrm{min}$ to $140^{\circ} \mathrm{C}, 2 \mathrm{~min}$ at $140^{\circ} \mathrm{C}, 5^{\circ} \mathrm{C} / \mathrm{min}$ to $200^{\circ} \mathrm{C}, 5 \mathrm{~min}$ at $200^{\circ} \mathrm{C}, 8^{\circ} \mathrm{C} / \mathrm{min}$ to $250^{\circ} \mathrm{C}, 1 \mathrm{~min}$ at $250^{\circ} \mathrm{C}$.

Identification and quantitative analyses of the peaks of volatile compounds in the samples analysed were made by comparison of their retention time with those of pure standards and internal standards.

\section{Results and discussion}

Technological characteristics of selected yeasts

For grape inoculation, three yeast strains were chosen from a collection of 104 strains isolated from fermenting marcs in different years and storage conditions, together with the commercial $S$. cerevisiae strain FR95, added as a control. The yeasts were isolated during the ensilage period of grape marcs of different origin (from Moscato or Prosecco grape varieties), or marcs subjected to different treatments (e.g. acidification). All strains from the collection were characterised by mtDNA restriction analysis at strain level and subsequently evaluated for their technological properties by growing in synthetic must. Yeast strain AR-1 was isolated from Prosecco acidified grape marc, NM-12 from Moscato pomace and TV-15 from a pool of grape pomace of different varieties that underwent high temperature stress $\left(35-40^{\circ} \mathrm{C}\right)$ during storage. All yeasts chosen were identified 
genetically as $S$. cerevisiae by sequence analysis of the D1/ D2 domains of 26 S rDNA (Kurtzman and Robnett 1998). Some oenological properties of the three selected strains are reported in Table 1. Although the commercial strains FR95 and NM-12 had higher fermentation vigour (sugar consumption during the first $48 \mathrm{~h}$ of fermentation), strain AR-1 was able to complete sugar transformation 4 days earlier and, together with TV-15, showed a better ability to transform varietal aromas present in raw material, linked to its high values of $\beta$-glucosidase activity. Concerning hydrogen sulphide production, TV-15 showed the lowest level among the strains chosen.

\section{Yeast-guided solid fermentations}

Natural yeast and bacterial populations were present in grape marcs at the beginning of the storage period, from $10^{5}$ to $10^{6} \mathrm{CFU} / \mathrm{g}$ pomace, with the yeast genus Hanseniaspora being the most represented (Bovo et al. 2008). In order to avoid any influence of autochthonous microflora on the fermentation process, a thermal treatment for $20 \mathrm{~min}$ at $72^{\circ} \mathrm{C}$ of grape marcs was performed, allowing a reduction of 1-2 $\log$ units. Pasteurised grape marcs were then transferred to modified Erlenmeyer flasks, pressed to avoid the presence of air pockets and inoculated to obtain a yeast population of between 1 and $3 \times 10^{6} \mathrm{CFU} / \mathrm{g}$ pomace, similar to that for must. Part of the raw material was used to set up noninoculated and non-pasteurised controls, with the aim of evaluating the contribution of natural yeasts to the aromatic profile obtained after distillation of fermented grape marcs.

Yeast dynamics and sugar consumption

At the beginning of fermentation (T0), and after 2 (T2), 5 (T5) and 8 (T8) days, quantitative analyses of yeast population and reducing sugars concentration were performed (Fig. 1).

In both the inoculated grape pomace and in the untreated control, yeast populations reached stationary phase within $48 \mathrm{~h}$, since no further increase in yeast concentration was observed after 2 days of incubation. Grape marcs inoculated with strains AR-1 and TV-15 reached the lowest yeast concentration, comparable to that of the control. Colony morphology on WL medium was characterised to detect the main yeast groups present at each sampling time (Cavazza et al. 1992). After 2 days of fermentation, the inoculated grape pomace contained a percentage of higher than $95 \%$ of colonies with typical $S$. cerevisiae morphology, i.e. white, light-green colour and smooth surface. This result was confirmed by mtDNA analysis on ten colonies collected from each inoculated sample. All the isolates analysed from marcs inoculated with AR-1 strain (Fig. 2), with NM-12, with TV-15 and with FR95 strains (data not shown) shared the electrophoretic profile of the inoculated strains, thus confirming their prevalence over the indigenous microflora. On the contrary, on WL medium control grape marcs contained, at the beginning of fermentation and after 2 days, $90 \%$ and $60 \%$ deep-green colonies, respectively, thus revealing a considerable presence of non-Saccharomyces yeast species.

The presence of $100 \%$ white colonies on WL medium after 5 and 8 days suggested the dominance of Saccharomyces strains at later timepoints. A remarkable decrease in sugar content occurred after just 2 days in all inoculated marc samples, indicating that fermentation was proceeding rapidly, as proven by complete sugar degradation within 5 days. In non-inoculated grape pomace, a slower fermentation dynamics was recorded, leading to sugar consumption after 8 days, linked to the slower development of the $S$. cerevisiae population.

Table 1 Oenological characteristics of yeast strains inoculated in grape pomaces for laboratory-scale fermentations. Fermentation performances were detected in synthetic must

\begin{tabular}{|c|c|c|c|c|c|c|c|c|}
\hline Strain & $\begin{array}{l}\text { Sugar } \\
\text { transformation } \\
\text { at } 2 \text { days }^{\mathrm{a}}\end{array}$ & $\begin{array}{l}\text { Sugar transformation } \\
\text { at } 7 \text { days }^{\mathrm{a}}\end{array}$ & $\begin{array}{l}\text { Sugar } \\
\text { transformation } \\
\text { at the end of } \\
\text { fermentation }^{\mathrm{a}}\end{array}$ & $\begin{array}{l}\text { Days of } \\
\text { fermentation }\end{array}$ & $\begin{array}{l}\text { Sensory } \\
\text { evaluation }\end{array}$ & $\mathrm{H}_{2} \mathrm{~S}$ production ${ }^{\mathrm{b}}$ & $\begin{array}{l}\text { Resistance } \\
\text { to } \mathrm{SO}_{2} 100 \mathrm{mg} / \mathrm{l}^{\mathrm{c}}\end{array}$ & $\beta$-glucosidase $\mathrm{d}^{\mathrm{d}}$ \\
\hline NM-12 & 7.1 & 18.8 & 20.2 & 15 & Positive & High & Sensitive & $1.7 \pm 0.1$ \\
\hline AR-1 & 6.3 & 17.4 & 20.0 & 11 & Neutral & High & Resistant & $3.7 \pm 1.4$ \\
\hline TV-15 & 4.8 & 16.9 & 20.0 & 15 & Neutral & Medium & Resistant & $5.8 \pm 0.9$ \\
\hline FR95 & 7.1 & 17.4 & 19.3 & 15 & Positive & High & Resistant & Not detected \\
\hline
\end{tabular}

${ }^{\text {a }}$ Expressed as $\mathrm{g} / 100 \mathrm{ml}$ synthetic must

${ }^{\mathrm{b}}$ Relative to the intensity of brown colour on Biggy agar medium

${ }^{\mathrm{c}}$ Determined in synthetic must on the basis of growth after $48 \mathrm{~h}$ in comparison with a control without sulphur dioxide by measuring the culture optical density at $600 \mathrm{~nm}$

${ }^{\mathrm{d}}$ Expressed as $\mu \mathrm{mol}$ of substrate consumed 
Fig. 1 Dynamics of yeast population (a) and sugar consumption (b) in grape marcs.

- Control heat-treated and noninoculated; • inoculated with strain FR95; $\diamond$ inoculated with strain NM-12; $\nabla$ inoculated with strain TV-15; * inoculated with strain AR-1

\section{a}

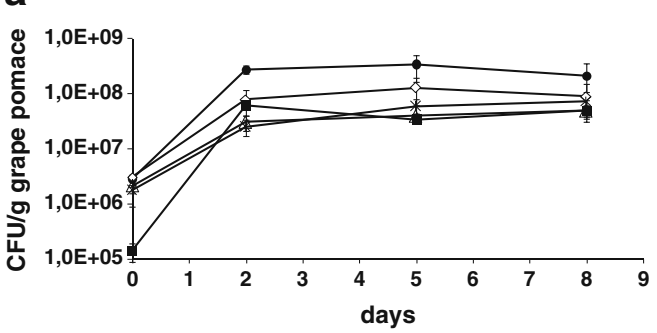

b

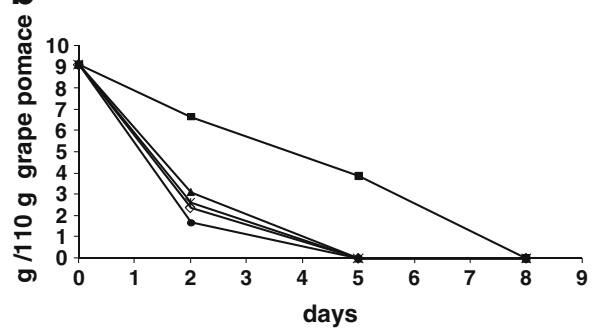

As regards $\mathrm{pH}$, the initial value of unfermented grape pomace was 4.4 and no relevant variation was observed during the period of fermentation, with any decrease always comprising between 0.2 and 0.3 units.

Aromatic compounds produced during fermentation

After 2, 5 and 8 days of fermentation, inoculated and control grape marcs were submitted separately to distillation by current steam extraction. The resulting water-alcohol solutions had an ethanol content of approximately $10 \%(\mathrm{v} / \mathrm{v})$, therefore a preliminary extraction step with organic solvent was necessary to concentrate volatile compounds. Previous studies have shown that different solvents may be used to efficiently extract the various molecules recovered from wine or distillate. Ortega et al. (2001) proved that dichloromethane was the most efficient solvent to resolve a wide range of compounds. In this work, the levels of the most important aromas formed during alcoholic fermentation (higher alcohols, esters, acetaldehyde, acetoin) and some varietal compounds commonly found in Grappa (hexanal, trans-2-hexenal, geraniol, linalool, nerol, $\beta$-damascone) were determined by gas chromatography.

Higher alcohols are secondary products derived mainly from yeast nitrogen metabolism, and are quantitatively the most abundant group of volatile compounds in distilled alcoholic drinks (Nykänen 1986), contributing significantly

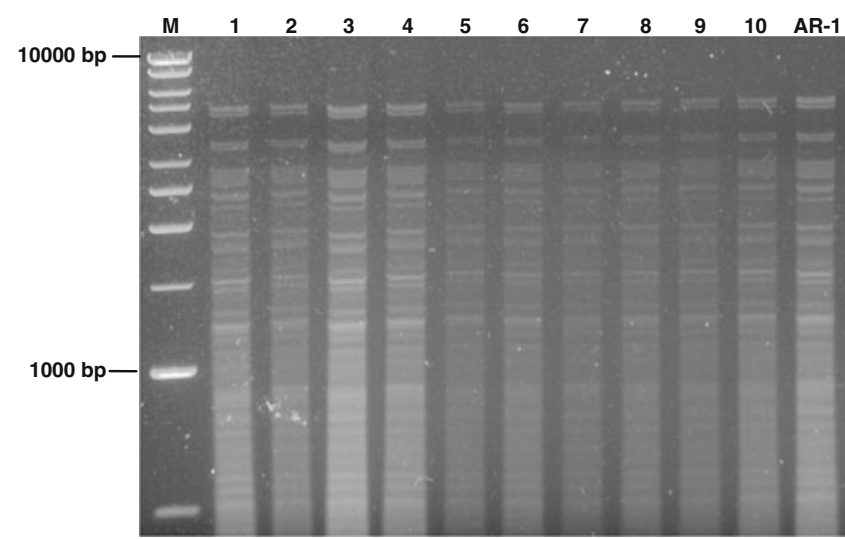

Fig. 2 Agarose gel electrophoresis of HinfI mitochondrial DNA (mtDNA) analysis of isolates from marc fermentation inoculated with AR-1 strain after 2 days. Lanes: 1-10 Marc isolates, AR-1 AR-1 strain, M 1-kb molecular ladder (Amersham) to their sensory properties (Silva et al. 1996). Good fermenting yeasts, such as $S$. cerevisiae, generally produce high levels of secondary alcohols, whereas yeasts common in the vineyard, such as Hanseniaspora uvarum, usually do not (Romano et al. 2003). Figure 3 reports the kinetics of n-propanol, n-butanol, $\beta$-phenylethanol and isoamyl alcohol production during the storage period. Our data show that the total amount of fusel alcohols is higher in inoculated grape marcs, thus indicating the strong impact of the introduced yeasts. In all inoculated marcs, a relevant increase was observed after 5 days, when relevant changes in metabolism are likely to occur following sugar exhaustion. Strains TV-15 and FR95 stand out for the increase in n-butanol production and for the high concentration of $\beta$-phenylethanol after 8 days, respectively.

Esters constitute the most interesting class of flavour volatile compounds in alcoholic beverages because of their fruity and flowery notes (Nykänen 1986; Verstrepen et al. 2003). Concentrations of the main esters produced by yeasts, namely ethyl acetate (solvent-like aroma), isoamyl acetate (banana), phenylacetate (flowery), and mediumchain fatty acid ethyl esters such as ethyl caproate and ethyl caprylate (fruity), were determined (Fig. 4). Generally, an increase in concentration was observed with time, with the highest values reached after 8 days of storage. Inoculated grape marc generally showed greatest amounts with respect to the control, as observed for higher alcohols. As regards single esters, ethyl acetate, considered one of the most important esters because of its unpleasant flavour, seemed to increase slightly throughout the whole period, both in inoculated and in control marcs. On the contrary, the concentrations of isoamyl acetate, phenylacetate and ethyl caprylate increased strongly after 5 days of fermentation, as was also the case for higher alcohols production. Strain AR-1 is a good producer of ethyl caprylate, and FR95 releases the highest quantities of phenylacetate as well as its precursor $\beta$-phenylethanol.

In addition to the main fermentative aromas contributed by yeasts, some aromatic substances of plant origin that greatly affect Grappa flavour were investigated to verify the influence of yeast growth on their concentrations. Hexanal and trans-2-hexenal, two aldehydes that confer a herbaceous and fat note (Flamini 2005), were detected at low levels. Values ranging from 5 to $10 \mu \mathrm{g} / \mathrm{ml}$ were found in all samples 
Fig. 3 Higher alcohols production during marc storage. a 1-Propanol, b 1-Butanol, c Isoamyl alcohol, $\mathbf{d}$

$\beta$-phenylethanol. - Control heat treated and non-inoculated;

- inoculated with strain FR95;

$\diamond$ inoculated with strain NM-12;

$\triangle$ inoculated with strain TV-15;

* inoculated with strain AR-1
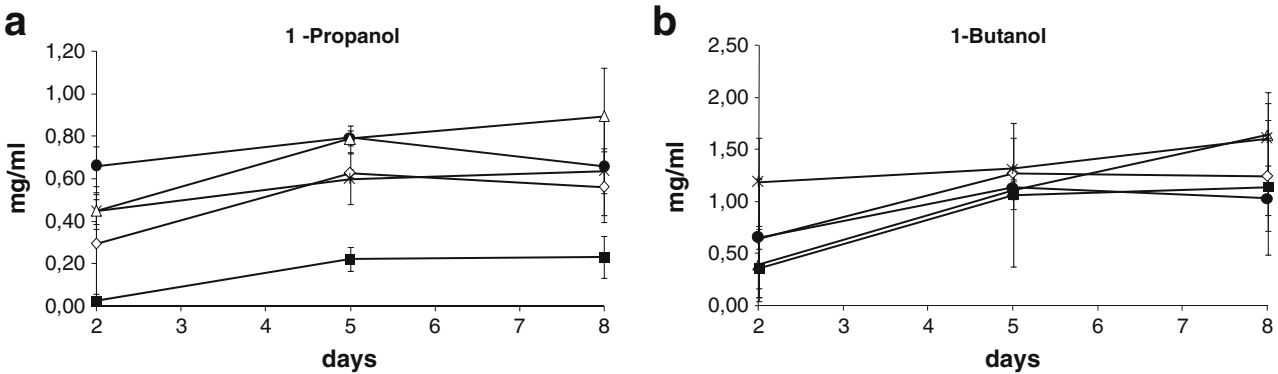

C

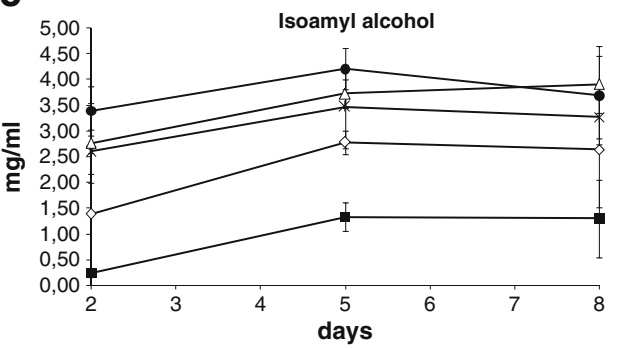

d

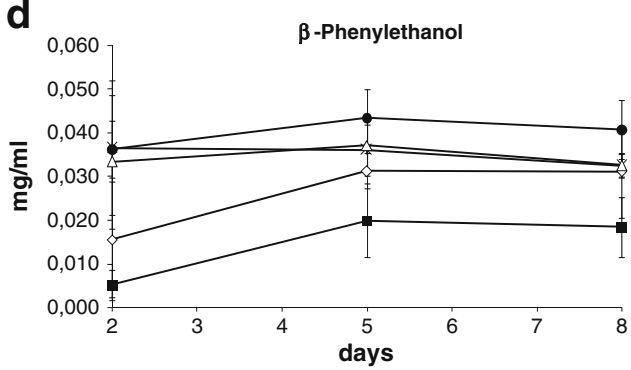

analysed after 8 days, and these values did not seem to be affected by the presence of inoculated yeasts. Moreover, some varietal grape compounds present in the Prosecco cultivar were considered: linalool, nerol and geraniol were the most prevalent terpenols, and $\beta$-damascone was prevalent among the norisoprenoid compounds (Calò et al. 2001), with concentrations very close to the detection limit of gaschromatography. In particular, yeast inoculation seems to
Fig. 4 Ester production during marc storage. a Ethyl acetate, $\mathbf{b}$ isoamyl acetate, $\mathbf{c}$ ethyl caproate, $\mathbf{d}$ ethyl caprilate, $\mathbf{e}$ phenylacetate. Control heat-treated and non-inoculated; - inoculated with strain FR95;

$\checkmark$ inoculated with strain NM-12; $\triangle$ inoculated with strain TV-15;

* inoculated with strain AR-1 a
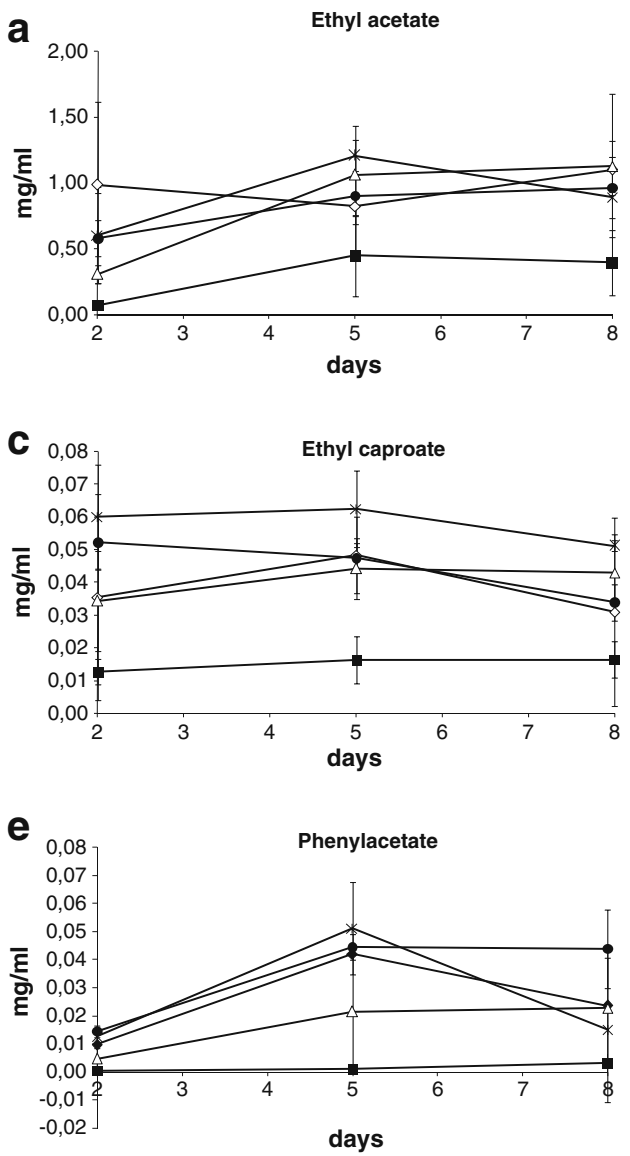

b
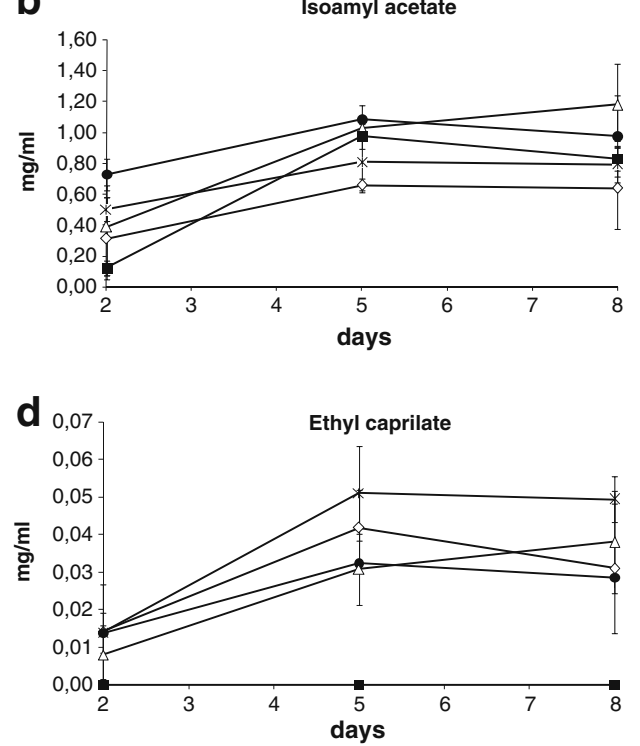
negatively influence the concentration of geraniol, which, after 8 days, was $3-4 \mu \mathrm{g} / \mathrm{ml}$ in all inoculated grape marcs, while reaching $12 \mu \mathrm{g} / \mathrm{ml}$ in the non-inoculated control.

Other molecules that are often detrimental to the quality of the spirit were taken into account. Acetaldehyde, which gives an unpleasant taste to the distillate if present at concentrations above $100-150 \mathrm{mg} / 100 \mathrm{ml}$ anhydrous alcohol (Di Stefano and Ciolfi 1982), and which is generally ascribed to non-Saccharomyces yeast metabolism, was found in slightly higher concentration in control grape marcs, where a non-Saccharomyces microflora had developed during the first period of storage. In fact, its concentration in uninoculated grape pomace was $0.12 \mathrm{mg} / \mathrm{ml}$ after 5 days, while all the inoculated grape marcs showed values ranging from 0.05 to $0.07 \mathrm{mg} / \mathrm{ml}$. A similar trend was observed for acetoin, highly produced by non-Saccharomyces yeasts such as Hanseniaspora (Romano et al. 1996). In the non inoculated control, a strong increase, up to $40 \mu \mathrm{g} / \mathrm{ml}$ after 5 days, was observed when native microflora was still fermenting sugars into alcohol, while in the inoculated marc the level was $3-5 \mu \mathrm{g} / \mathrm{ml}$ when the fermentative activity of inoculated yeasts was completed.

Methanol, which has well-known severe effects on human health, as its ingestion in large doses can produce blindness or even death, is generated by native plant pectin methyl esterases (Zocca et al. 2007). An increase in methanol concentration was detected during days 5-8 of storage: in this period, the concentration increased from $0.05 \mathrm{mg} / \mathrm{ml}$ to 0.20 and $0.30 \mathrm{mg} / \mathrm{ml}$, respectively, in the case of NM-12 and FR95, the most vigorous strains, whose growth might have influenced the plant matrix, favouring conditions for plant pectin methyl esterase activity. Considering that the distillates contained $10 \%$ ethanol, the concentrations of acetaldehyde, methanol and acetoin found were much lower than European and US legal limits $(1 \mathrm{~g}$ per $100 \mathrm{ml}$ of alcohol anhydrous, and $280 \mathrm{mg} /$ $100 \mathrm{ml}$ of $40 \%$ alcohol, respectively). Figure 5 reports the kinetics of acetaldehyde, methanol and acetoin production during the storage period.

Finally, no relationship was found between yeast activity and the presence of 2-butanol, considered a marker of marc quality, since its presence appears linked to undesired side fermentations (Masino et al. 2009). We detected concentrations from 10 to $15 \mu \mathrm{g} / \mathrm{ml}$, well below the European legal limit (EC regulation 1576/89; EEC 1989).

\section{Conclusions}

The results from this study demonstrate that inoculation of yeast strains has a great impact on fermentation of grape marc during storage. Firstly, as all yeast strains introduced were able to prevail over the autochthonous microflora, sugar consumption was faster than in the non-inoculated control, terminating fermentation at least 3 days earlier. Nevertheless, the main differences were found in the aroma profile drawn from gas chromatography analysis of the distillates. In fact, in the inoculate grape marc, a greater number of molecules of fermentative origin (higher alcohols and esters) were produced compared to the control. The only ester found at the same level in all marcs was isoamyl acetate, whose production is linked mainly to non-Saccharomyces yeasts, such as Pichia and Hanseniaspora (Plata et al. 2003; Rojas et al. 2001). In the case of uninoculated grape marc we demonstrated that, during the first 3 days of storage, yeast microflora comprised mostly non-Saccharomyces species.

Our results suggest the use of yeast inoculation not only for vinification but also for improving the quality of Grappa
Fig. 5 a Acetaldehyde, b methanol, and $\mathbf{c}$ acetoin production during marc storage. - Control heat-treated and noninoculated; • inoculated with strain FR95; $\diamond$ inoculated with strain NM-12; $\triangle$ inoculated with strain TV-15; * inoculated with strain AR-1 a

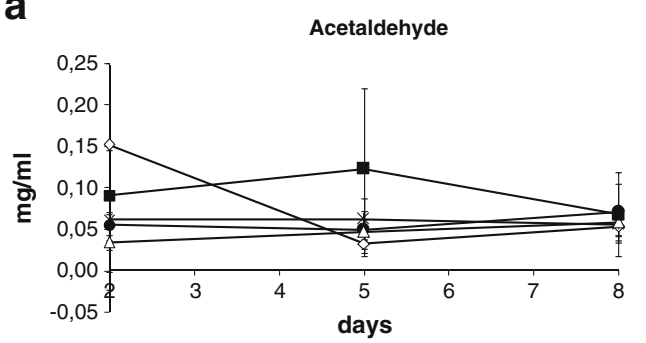

C

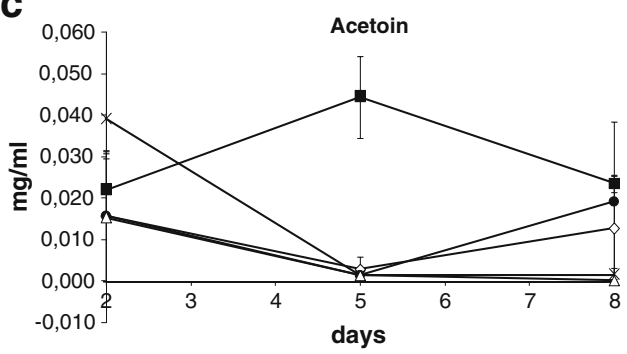

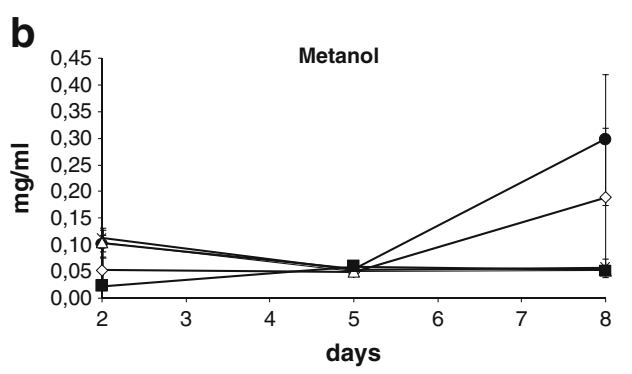

\section{b}

,


spirit. In such cases, yeast addition could lead not only to the increased development of aroma molecules, but also to the control of spoilage microorganisms that could greatly affect product quality.

Further studies are needed to better understand the role of yeast strains in emphasising differences in the quality of the distillate, even taking into account the prolonged incubations of marcs.

Acknowledgements Luca Liverani is gratefully acknowledged for skilful technical assistance. This work was supported in part by Regione Veneto and Provincia di Treviso.

\section{References}

Bovo B, Andrighetto C, Carlot M, Corich V, Lombardi A, Giacomini A (2008) Yeast population dynamics during pilot-scale storage of grape marcs for the production of Grappa, a traditional Italian alcoholic beverage. Int J Food Microbiol 129(3):221-228

Calò A, Scienza A, Costacurta A (2001) Vitigni d'Italia. Edagricole, Bologna

Cavazza A, Grando MS, Zini C (1992) Rilevazione della flora microbica in mosti e vini. Vignevini 9:17-20

Da Porto C (2002) Volatile composition of "grappa low wines" using different methods and conditions of storage on an industrial scale. Int J Food Sci Technol 37:395-402

Delfini C (1995) Scienza e Tecnica di Microbiologia Enologica, Ed. Il lievito. Asti, Italy

De Rosa T, Castagner R (1994) Tecnologia delle grappe e dei distillati d'uva. Edagricole, Bologna

Dice LR (1945) Measures of the amount of ecologic association between species. Ecology 26:297-302

Di Stefano R, Ciolfi G (1982) Produzione di acetaldeide da parte di stipiti di lieviti di specie diverse. Riv Vitic Enol 35:474-480

EEC (1989) Council Regulation No. 1576/89 of 29 May 1989. http://eur-lex.europa.eu/LexUriServ/LexUriServ.do?uri=CON SLEG:1989R1576:20070101:EN:PDF

Fia G, Giovani G, Rosi I (2005) Study of $\beta$-glucosidase production by wine-related yeasts during alcoholic fermentation. A new rapid fluorometric method to determine enzymatic activity. J Appl Microbiol 99:509-517
Flamini R (2005) Some advances in the knowledge of grape, wine and distillates chemistry as achieved by mass spectrometry. J Mass Spectrom 40:705-713

Kurtzman CP, Robnett CJ (1998) Identification and philogeny of ascomycetous yeasts from analysis of nuclear large subunit $(26 \mathrm{~S})$ ribosomal DNA partial sequences. Antonie van Leeuwenhoek 73:331-371

Masino F, Montevecchi G, Riponi C, Antonelli A (2009) Composition of some commercial grappas (grape marc spirit): the anomalous presence of 1, 1-diethoxy-3-methylbutane: a case study. Eur Food Res Technol 228:565-569

Nykänen L (1986) Formation and occurrence of flavour compounds in wine and distilled alcoholic beverages. Am J Enol Vitic 37:84-96

Ortega C, López R, Cacho J, Ferreira V (2001) Fast analysis of important wine volatile compounds. Development and validation of a new method based on gas chromatographic flame ionization detection analysis of dichloromethane microextracts. J Chromatog A 923:205-214

Plata C, Millan C, Mauricio JC, Ortega JM (2003) Formation of ethyl acetate and isoamyl acetate by various species of wine yeasts. Food Microbiol 20:217-224

Querol A, Barrio T, Huerta T, Ramon D (1992) Molecular monitoring of wine fermentations conducted by active dry yeast strains. Appl Environ Microbiol 58:2948-2953

Rojas V, Gil JV, Pinaga F, Manzanares P (2001) Studies on acetate ester production by non-Saccharomyces wine yeasts. Int J Food Microbiol 70:283-289

Romano P, Brandolini V, Ansaloni C, Menziani E (1996) The production of 2, 3-butanediol as a differentiating character in wine yeast. World J Microbiol Biotechnol 14:649-653

Romano P, Fiore C, Paraggio M, Caruso M, Capece A (2003) Function of yeast species and strains in wine flavour. Int J Food Microbiol 86:169-180

Silva ML, Malcata FX, De Revel G (1996) Volatile contents of grape marcs in Portugal. J Food Compos Anal 9:72-80

Verstrepen JK, Van Laere SDM, Vanderhaegen BMP, Derdelinckx G, Dufour J, Pretorius IS, Winderickx J, Thevelein JM, Delvaux FR (2003) Expression levels of the yeast alcohol acetyltransferase genes $A T F 1, L g-A T F 1$, and $A T F 2$ control the formation of a broad range of volatile esters. Appl Environ Microbiol 69:5228-5237

Zambonelli C (2003) Microbiologia e Biotecnologia dei Vini. Edagricole, Bologna

Zocca F, Lomolino G, Curioni SP, Lante A (2007) Detection of pectinmethylesterase activity in presence of methanol during grape pomace storage. Food Chem 102:59-65 